\title{
Managing Consumer Mythology: The Green Consumption of E10 Fuel
}

\author{
Prof. Pepukayi Chitakunye \\ School of Economic and Business Sciences, University of the Witwatersrand, South Africa. \\ Email: pepukayi.chitakunye@wits.ac.za \\ Mr. Fanny Saruchera \\ School of Business Science and Management, Chinhoyi \\ University of Technology, Zimbabwe. \\ Email: sarucheraf@yahoo.com
}

Mrs. Evelyn Derera

School of Management, IT \& Governance, P Bag X01, Scottsville, Pietermaritzburg, University of KwaZulu-Natal, South Africa.

Email: dererae@ukzn.ac.za

\section{Dr. Amandeep Tarkhar-Lail}

University of Bedfordshire, University Square, Luton, Bedfordshire, United Kingdom Email: Amandeep.Takhar@beds.ac.uk

\author{
Doi:10.5901/mjss.2014.v5n20p1098
}

Abstract

The purpose of this article is to explore how myths become meaningful to consumers of ethanol-blended petrol (E10) in Zimbabwe. The last decade has seen the emergence and increasing significance of being green. Consequently, green consumption has become a topic of increasing significance amongst consumers and scholars. This study adopted a multiplemethod research strategy, that included 32 key informant in-depth interviews, and 150 questionnaires completed by ordinary consumers. The study unpacks how myths can be used as a symbol of resistance where there is a wide range of product choice. We find that the market acceptance of Zimbabwe's E10 remained pessimistic, yet elsewhere in the world, the same blend has been packaged as a 'premium, super brand'. Drawing from the findings, we argue that consumers engage with myths in their everyday lives, and the meanings associated with myths are transferred to the 'green fuel' brands. Although the consumption of E10 fuel is important to the maintenance of a green society, it should be understood that there are consumer misconceptions ranging from technical fuel composition, engine compatibility, mixed pricing perceptions and policy-related issues. Revealing how 110 fuel has been a success story in other countries, our study demonstrates how marketing education can be employed to create awareness of the benefits for consuming green fuel. Our findings also reveal how myths slowly die a natural death when product choice becomes limited. These findings contribute to an understanding of how consumer misconceptions about a product or service can impact product image and sales.

Keywords: Consumer myths, commercialization, blended fuel (E10), green consumer, perceptions

\section{Introduction}

Myths have come of age within consumer research (Brown et al., 2013). In fact, consumer researchers have explored the role of myths within consumer behaviour extensively (Levy, 1981; Holt, 2004; Thompson, 2004). Consumer research has focused on the pursuit of heroic masculinity (Holt and Thompson, 2004); marketplace mythology and the discourse of power (Thompson, 2004) and legendary brands (Vincent, 2002). More influential scholarly work has focused on the manner in which brands become mythical resources and the impact of such brands on consumer behaviour and other marketing outcomes (Atkin, 2004; Thompson and Tian, 2008). In fact within Kristensen et al., (2011) study of mythology relating to milk consumption within a Danish community they suggest that "marketplace resources are situated in mythological scripts and used to articulate ideological meanings" (p.198). However, the majority of this work has largely 
drawn insights from consumers in well developed economies that tend to be based in the Western context, who are often surrounded with an abundance of choice for consumer goods. Therefore bringing the case of emerging economies to this theoretical debate is an interesting and significant contribution to this field because of the economic uncertainties surrounding the supply of basic goods such as fuel. For example, the dawn of Zimbabwe's independence saw the government dedicating substantial resources towards the establishment and capacity building of centres for innovation, with the intention of creating demand and making basic goods and services locally available. Within this context, emerged the development and advocacy of the use of bio fuels. During the 1980s, all petrol sold in this country was a petrolethanol blend, with the ethanol percentage sometimes reaching 20 percent (Zindoga, 2012). No one minded. All cars worked as designed (Zimbabwe Energy Regulatory Authority, 2012). In 2011, more than 20 years post-independence, the government resurrected the bio fuel sector, with the objective of increasing energy independence, creating jobs in rural areas and combating climate change. All things being equal, up to 20 percent of fuel imports in Zimbabwe were to be replaced by biodiesel and ethanol (from sugarcane). Consequently, approximately US $\$ 600$ million was invested into the mammoth ethanol project at Chisumbanje in the Manicaland Province of Zimbabwe (Zindoga, 2012).

The rise of contemporary environmentalism is now perceived as an element of environmental reforms in many countries (Conolly and Prothero, 2013) and contributes to the increasing focus on "ethical consumerism" (Thompson and Coskunner-Bali, 2007: 292) where consumers are deeply committed to socially responsible values. Within this context, the consumption of green fuels such as E10 ascribes consumers with the responsibility to address environmentally friendly lifestyles. Yet, in Zimbabwe, the myths surrounding the consumption of E10 fuel ranged from technical issues concerning the fuel's composition to mixed pricing perceptions and issues concerning "consumer morality" (Wilk, 2002: 245) as consumption inevitably raises moral issues within every culture (Wilk, 2002). The emergence of the green consumer in Zimbabwe offers an opportunity to examine the everyday myths surrounding the consumption of E10 fuel, with the intention of providing a better platform for informed debates. Given the increasing need for evidence-based policy making, there is a transparent need for research that will inform policy makers, fuel distribution companies, and consumers to fully comprehend the true nature and characteristics of E10 fuel. Hence the significance of this work to scholarly writings within consumer research and consumer mythology. Within this context, the specific objectives that this study is grappling with are:

- To understand the myths that encourages or discourages the consumption of green fuel (E10) in an emerging economy.

- To identify the characteristics of green fuel (E10) in an emerging economy in relation to international standards

Given these objectives, we therefore postulate that marketing must focus on the obvious benefits of using E10. With the hope that positive marketing efforts can, in turn remove any negative perceptions (misconceptions) or myths on the quality, pricing, efficiency, reliability and technicalities of E10 which will ultimately lead to a positive response from the public (consumers) and in turn increase sales of the product.

\section{Blended Fuel Consumption in other Countries}

Much of the focus on green consumers has centred on developed economies, and how they adopted more ethanolblended fuels as opposed to unblended fuels (Gentile, 2008). However, not all countries have adopted 10\% ethanol. For example, Brazil has adopted as much as $20 \%$ in some of its applications. Rising oil prices and apprehension about global warming have prompted governments to rethink their energy supply policies (Strengers, 2011). Such countries include U.S.A., China, Australia, India and Brazil (the world's top producer), among many others. Within this, there is an interest in Brazil's applications. For example, Japan's interest in Brazil's ethanol was prompted in 2004 when Prime Minister Junichiro Koizumi visited an ethanol production facility in Brazil and said his country was interested in the alternative fuel as a means of meeting the demands of the global environmental agreement signed under the Kyoto Protocol (Renewable Fuel Association, 2012). The Brazil-Japan ethanol relationship has grown significantly since then, with the announcement in 2005 of the formation of the Brazil-Japan Ethanol Company, a partnership between Petrobras and Japan's Nippon Alcohol Hanbai. Coincidentally, Japan serves as the major source of Zimbabwe's second hand cars, the very same cars that are expected to be using the ethanol fuel.

While consumers within Japan have successfully advocated for the use of ethanol, the Zimbabwean consumers demonstrated resistance, even though measures have been taken to ensure engine compatibility with the ethanol fuel. In fact, Japan has adopted ethanol-blended fuel since 2005. Therefore, this study sought to understand why there is consumer resistance to the E10 fuel in the Zimbabwean market. Equally important is to understand whether there are lessons that Zimbabwe can learn from developed economies such as Japan, and how this can help to improve the adoption of ethanol blended fuel. 
According to Durgee (1988: 532) "people tell stories to each other in order to share each other's experiences", i.e. vicarious enjoyment and they also enjoy the suspense awaiting the outcome or climax (Benjamin, 1969). To this end, Levy (1981) argues that shared folklore and myths promote group solidarity, and provide self-esteem and status to those who tell the story. Such has been the case with the marketing of E10 fuel in Zimbabwe.

\section{Myths Surrounding Ethanol Fuels in Zimbabwe}

Despite the enormous, yet scarce resources that have been invested into the ethanol project, the initial consumer response in adopting the product has remained minute. Consumers driving into service stations frequently found a queue at the unblended petrol pump, while the E10 (Blend) pump is occasionally attended, with very few vehicles. It is apparent that consumers engage in storytelling and share their misconceptions regarding the fuel quality, price, efficiency, as well as other areas. Instead, motorists would rather waste time and money, with the last litre in their fuel tanks in search of their regular imported unblended fuels. These have some resemblance with the myth of green marketing as discussed by Smith (1998).

This means Zimbabwe was still highly dependent on the cost inefficient imported fuel, regardless of huge stocks of a locally produced fuel. At the height of these myths, the company producing ethanol for the blended petrol, Green Fuel Limited, suspended production as it ran out of storage space after reaching its full stock of 10 million litres. As a result, the company retrenched about six hundred employees (Zindoga, 2012) after the two year old plant was shut down. Several perceptions and stories circulated, relating to E10 fuel in Zimbabwe. Some stories expressed doubts in the composition of E10 fuels, and its compatibility to local cars, and go on to question its impact on car performance. These myths resonated with consumers, and the tale suggested that E10 fuel gets consumed too quickly, while others simply did not believe in the product. However, this was not necessarily due to personal consumer experience but merely the negative spread of word of mouth, demonstrating how consumer mythology impacts consumer actions.

\section{Consumer Mythology}

Through the history of qualitative consumer research theory, there are two key forms of responses given by respondents about myths, that is, perceptions and stories (Levy, 1981; Durgee, 1988; Kozinets, 2008; Zhao and Belk, 2008). It is the perceptions and the stories that result in myths. Within marketing and consumer research, the term myth is used to describe consumption stories that are generally believed to be true, but in actual reality they are false.

Levy (1981), defines a myth as a belief or narrative that a group of people accept as true. In fact, he suggests that "the purpose of myth is to provide a logical model capable of overcoming contradictions or paradoxes in natural and social experience" (Levy, 1981:51). In a similar vein, Thompson (2004) suggests that a market mythology is a collection of "discourses that seeks to channel consumers' identities and lifestyles in a particular ideological direction" (Thompson 2004:170). Interestingly, Kozinets (2001) suggests that myths integrate social groups by proposing meaning for social life and outlining appropriate modes of conduct. Myths help consumers to understand their place in society, as in utopian myths, as well as dystopian myths (Kozinets, 2001), or gnostic myth (Thompson, 2004). Further, Holt (2004) suggests that the market mythology of simple living resolves the cultural contradictions by providing the individual with a toolkit of authentic (sub-culturally-legitimated) myths to counter the hegemonic ideology. Consumer mythology is in fact also interpreted as consumer story telling theory and is of course highly influenced by consumer word of mouth. Therefore, it is apparent that the structure of consumer word of mouth is indicative of the form that the consumer story or myth will take. In fact, Siddiqui et al., (2008) suggest that the consumer story is best described as a consumption narrative. Further, Siddiqui et al., (2008: 810) suggest that "like other facets of social and cultural life, consumption narratives permeate the marketplace, but because marketplaces are ruled and governed by marketers, these narratives are generally more marketing communication inspired than what might be termed consumer originals". Nevertheless, Holt and Thompson (2004: 426) do believe that dramatic consumption stories must be scripted "either by experiential service providers or within the institutional structure of a consumer sub-culture". What's more, it is imperative that we consider matters from the consumers' perspective and consider the "ideological influences that shape the actions of commercial mythmakers" (Thompson, 2008: 145). Given this background, this study contributes to the field as it measures consumer perceptions about mythologies that surrounded the consumption of E10 fuel within Zimbabwe.

\section{Research methodology}

The research was carried out between 2010 and 2013. We adopted an exploratory perspective since the researchers 
intended to establish the realities surrounding E10 commercialisation, that is, what is really causing E10's failure within the Zimbabwean market. This helped in clarifying the researchers' understanding of the research problem. This study adopted a multiple-method research strategy to achieve the study's objectives. Multiple methods are increasingly being recognised for their ability to bring out multiple points of view to a research project, taking advantage of the strengths of each of the qualitative components to explain or resolve complex phenomena or results (Wallendorf and Arnould, 1991).

Data for this study was gathered in four phases. The first phase involved an appreciation of the status quo. This was achieved through a non-systematic review of different forms of publications (secondary sources) including newspapers, relevant websites and participatory observations. The researchers followed through the E10 news from the time the product was rolled out for commercialisation, its acceptance by distributors and final uptake by potential consumers. Some participatory observations were made by randomly driving in to some service stations in and out of Harare (capital city of Zimbabwe) where the fuel is being distributed. The primary intention of this was to obtain first-hand information about everyday consumer experiences and accumulate insights from the consumers themselves.

The second phase involved holding 32 key informant interviews with conveniently sampled service stations' staff (i.e. fuel attendants, station supervisors and station managers). The interviewees were conveniently selected from service stations that distribute, and those that do not distribute E10 fuel. During this phase, short, but structured interceptive interviews were held with 150 motorists randomly intercepted at these service stations. To participate in this research, respondents had to be aware of, or have been engaged in the usage of E10 fuel. The interceptive interview guide was divided into three sections: the first section dealt with motorist evaluations based on their experience with E10 (if any); the second section asked the respondents to rank the attributes (in the first section) in order of expectation / preference (regardless of past experiences), while the third section was concerned with their perceptions of E10 fuel and what they thought could be done to improve the situation.

The third phase involved a key informant telephonic interview with one of the senior managers from Green Fuel Limited Company. Anonymity of research participant was ensured for the success of the research project. The real issues facing the company and possible challenges were scrutinised. It is also during the interview that the research problem was confirmed, while technical issues involved in E10 fuel were clarified.

During the fourth and last phase, the researchers reviewed some success stories of E10 uptake in other countries. This involved an examination of publications on how those countries have managed to gain ethanol fuel acceptance in their respective countries. The researchers reviewed cases from Japan (the major suppliers of used cars to Zimbabwe), U.S.A, Brazil and China, who are on the lead regarding the adoption of blended fuels, some even using up to E85 (Gasparatos et al., 2013). The information gathered from the reviews, together with data collected from phases 1,2 and 3, was analysed and used to establish a way forward (roadmap) for the Zimbabwe's situation. Table 1 justifies the multiplestages in gathering data for this study.

Table 1: Multiple Data Collection Techniques

\begin{tabular}{|l|l|}
\hline Objective & Multiple Data Sources \\
\hline $\begin{array}{l}\text { To understand the nature of the research problem i.e. E10 } \\
\text { commercialization challenges }\end{array}$ & $\begin{array}{l}\checkmark \text { Published Material } \\
\checkmark \text { Participatory observations }\end{array}$ \\
\hline $\begin{array}{l}\text { To create an in-depth and rich account of E10 uptake and } \\
\text { issues arising }\end{array}$ & $\begin{array}{r}\checkmark \text { Key informant interviews with fuel Distribution } \\
\text { (service stations) staff (32) }\end{array}$ \\
\hline $\begin{array}{l}\text { To confirm the research problem and gain technical insights of } \\
\text { E10 }\end{array}$ & $\begin{array}{l}\checkmark \text { Key informant (telephonic) interview with Green } \\
\text { Fuel Limited. (1) }\end{array}$ \\
\hline $\begin{array}{l}\text { To appreciate customer perceptions on E10 fuel vis-à-vis their } \\
\text { expectations. }\end{array}$ & $\checkmark$ Short interceptive (service station) interviews (150) \\
\hline
\end{tabular}

During data collection process, respondents were not forced to partake in the study. Instead, the researchers had to first clarify the need for the research and how the study would impact the future of the country, the region and the world at large. Consent was thus obtained from the respondents before their participation in the study.

\section{Research Findings}

The findings discuss the E10 fuel brand through a mythological lens, with a view to unpacking this phenomenal within the context of everyday consumer lives. Firstly, we unpack the distribution of E10 fuel within Zimbabwe, followed by a discussion of consumer perceptions of the brand. Given that consumers look to global brands to create an "imagined 
global identity," a transnational "global myth" of belonging anchored in consumer culture (Holt et al., 2004), the study goes on to reflect on the successes or failure of E10 fuel within the global context as a way of reflecting on how branded products are a pre-eminent source of mythic and symbolic resources for consumer identity projects.

\subsection{Distribution of green fuel (E10)}

Through analysis of both primary and secondary data sets, we found that there are 197 service stations in Harare (ZERA, 2012). What also emerged was that, at that time, E10 was distributed in 59 stations, which represented $30 \%$ of service stations across different cities in Zimbabwe. It was also found that the first distribution point of E10 fuel in Zimbabwe (as at November 2012) was in Mutare, which is about $200 \mathrm{~km}$ from the plant, a clear indication that the product has not been sufficiently marketed and / or has not been accepted by its local consumers. However this could also possibly be due to unstable socio-economic relations between the firm and the local community. Our results reveal that E10's overall market coverage in Zimbabwe stands at $+/-17 \%$ (as at October / November 2012). Naturally, consumers' degree of new product trial tends to increase if the new product is easily accessible (Aggarwal et al., 1998).

Interestingly, when asked why they did not distribute E10, 83\% of the service stations who participated in the study indicated that though they would love to, they learnt from the current distributors of the product that E10 does not sell quickly; hence a slow sales turnover. This slow rate of sales can be attributed to the myths and confusion within the mindsets of the consumers and in fact is in line with the beliefs of Wilk (2002) as he suggests that consumers of developing economies are accused of accepting false idols. Further, this can be interpreted as a disconnection between these consumers and the wide spread global environmental problems. As the myths about E10 fuel spread, these consumers became more disconnected with the brand. From this, we share the view that consumption is embedded in social relations (Miller, 1998), and the way E10 fuel was discussed within different social relations. What's more, $76 \%$ of the service stations indicated the need for a third E10 fuel pump since they only have two pumps for unblended petrol and diesel only; while $14 \%$ were of the view that since it is not mandatory, they have every right to distribute what they felt is marketable to consumers. However $10 \%$ of the respondents did raise concerns relating to the price of E10, which they felt was too high to attract customers. As at November 2012, the E10 price ranged between $\$ 1.3$ and $\$ 1.49$ / litre versus $\$ 1.45$ - \$1.52 / litre (for unblended petrol) depending on location.

Significantly, social responsibility factored into the psyche of some service station owners as, $90 \%$ of the service stations that distributed E10 indicated that they did so because they felt that the product was environmentally friendly. Another reason cited was, patriotism as informants valued the fact that the product is $100 \%$ Zimbabwean, and as such, it needed their support. Providing consumers with a set of choices was also a reason for stocking and distributing E10. This important finding is consistent with studies that categorise green consumption practices as a form of political activity (see Connolly and Prothero, 2008) or a form of new political participation (Micheletti et al., 2004). Here, feelings of patriotism help to dispel some of the consumer myths about the green fuel.

Approximately $60 \%$ of the service stations expressed their satisfaction with E10 sales. The stations were located in low-density areas, especially in Harare (Avondale, Belgravia, Borrowdale etc). In contrast, $40 \%$ of the service stations that sold E10 fuel indicated that they were not impressed with E10 sales. For instance, one service station in Harare City centre indicated that they sold a daily average of about 20 litres of E10 fuel, compared to an average of +/-500 litres of unblended petrol. These findings were consistent with insights that emerged from our participatory observations.

\subsection{Myths that discourage or encourage consumption}

According to Connolly and Prethero (2008), consumers feel more interconnected with global environmental issues. Yet, we find that central to this are myths surrounding the consumption of green fuel. For example, of the 150 respondents, $113(75 \%)$ identified themselves with at least some level of awareness of E10 fuel while 37 (25\%) were not aware of the product. Our interest was on how the consumption of E10 fuels was initially perceived by consumers. Given that green consumers have families, parents, children, fellow workers, and so forth, their perceptions are often shared through social interactions. Given that consumption is embedded in social relations (Douglas, 2001), it can be argued that these social relations also encourage the consumption of myths surrounding E10 fuel. For example, of the 113 respondents who were aware of E10,31\% indicated that they have used and / or are using E10 while $69 \%$ have never tried using E10. The common stories that were transmitted were that E10 "destroys engines" and that it "gets used up quickly". However, significantly when probed as to whether they have proven these claims themselves, none of the motorists had actually proven anything themselves. This provides a clear indication that potential consumer education was needed at that time at a local and national level. We also found that the myths that surrounded E10 forced some companies to revise their 
policies, with the intention of stopping their drivers from fuelling and / or re-fuelling company vehicles with E10. This indicates how the misconceptions about E10 fuel in Zimbabwe filtered across different types of user groups, including individual consumers, and different organisations. Thus our findings confirm the power of word of mouth (Buttle, 1998; Libai et al., 2004; Keller, 2007) and peer influence on the attitudes, thoughts, and actions of an individual (Bristol and Mangleburg (2005). These findings are consistent with Tulloch and Lupton (2002) when they discuss the concept of fear and risk in relation to the discussion of consumption and the environment. We find that consumers of green fuels in Zimbabwe were at first fearful, and risk averse when it came to the consumption of the E10 brand. Consistent with Beck (1992), these emergent myths concern risks related to the hazards and insecurities associated with the E10 brand, especially when there were other product choices on the market.

On the other hand, of the 31\% who had used E10, 95\% expressed their satisfaction with E10 performance and indicated that they would recommend others to use the product. In fact, the study established that about $60 \%$ of these E10 advocates were products of positive word-of-mouth. The E10 advocates had the following "top three" reasons to adopt E10. These are, 1) E10 cleans your engine, tank and carburettor, 2) "I can alternate E10 blend with unblended petrol anytime" and 3) the whole world is going "green" why not rally behind?

However, reservations were relating to the price of E10. When reminded that of the total price, ethanol fuel was only $10 \%$ while $90 \%$ was still imported cost. The E10 advocates were of the view that Zimbabwe should move to higher ethanol blends (E15, E20, E25...up to E85) on the premise that this would lead to "lower price" and reduce the nation's dependency on imported fuel. Following from this, 53\% of the E10 consumers expressed their loyalty toward the ethanol blend and indicated that they would not consume any other fuel, as long as E10 was still available elsewhere. However, in the event of fuel shortages, $100 \%$ of the motorists who participated in this study disclosed that they would consume E10 fuel, regardless of price. This indicates that the myths can be dispelled if there is no choice. The analysis was followed by identifying the expectations of potential consumers of E10 fuel. These are the factors that motorists perceived they could consider in making an initial purchase of E10, and they included pricing, safety, compatibility, uniqueness, 'switchability', communication / assurance, availability and market support, as illustrated in table 2. Using a five point likert scale, respondents were asked to either agree or disagree with a set of evaluative statements where SA = strongly agree; $\mathrm{A}=$ agree; NS = not sure (neither agree nor disagree); $\mathrm{D}=$ disagree; SD = strongly disagree.

Table 2: Motorists' Perceptions on E10 Fuel

\begin{tabular}{|c|c|c|c|c|c|c|c|}
\hline & \multicolumn{9}{|c|}{ E10 Characteristics } \\
\hline Response & Uniqueness/Originality & Compatibility/Quality & $\begin{array}{c}\text { Communication/ } \\
\text { Assurance }\end{array}$ & $\begin{array}{c}\text { Safety \& environ- } \\
\text { friendliness }\end{array}$ & Availability & $\begin{array}{c}\text { Relative } \\
\text { Price }\end{array}$ & $\begin{array}{c}\text { Market } \\
\text { Support }\end{array}$ \\
\hline SA & 0.49 & 0.50 & 0.09 & 0.10 & 0.11 & 0.05 & 0.07 \\
\hline A & 0.29 & 0.18 & 0,05 & 0.40 & 0.07 & 0.06 & 0.11 \\
\hline NS & 0.12 & 0.05 & 0.17 & 0.15 & 0.14 & 0.20 & 0.10 \\
\hline D & 0.04 & 0.17 & 0.49 & 0.08 & 0.41 & 0.52 & 0.42 \\
\hline SD & 0.06 & 0.10 & 0.20 & 0.27 & 0.27 & 0.29 & 0.30 \\
\hline Total & 100 & 100 & 100 & 100 & 100 & 100 & 100 \\
\hline
\end{tabular}

For the purposes of this research (labelling), uniqueness relates to an innovation or product of its own kind. While an innovation could be unique, that may not guarantee its quality i.e. durability and fitness for intended purpose (Kotler, 1997). Communication is taken to relate to the degree to which E10 is promoted through awareness programmes. Availability relates to the respondents' rating on their access to E10 fuel. Relative price refers to the consumer perceptions with regards to E10 market price in comparison with unblended petrol, while market support relates to postE10 launch activities such as reminder promotions, customer service (back-up, follow-up, guarantees and warrantees) (Lamb et al., 1996).

While $73 \%$ of the respondents associated with E10 confirmed that the product was unique and of quality. It is nevertheless disheartening to realize that very little was done at that time to communicate and / or promote and fully educate the potential consumer markets of E10 and its usefulness. This was evidenced by higher aggregates of respondents who disagreed with regards to communication (79\%), availability (68\%), and market support (72\%). The majority (81\%) of the respondents perceive E10 pricing as unjustifiably too high for an indigenous innovation. This discouraged the successful commercialization and subsequent market uptake of E10 in the country, despite its apparent vast potential.

Agreeing with Levy (1981), and Thompson (2004), if we take the idea that myths are ways of organizing 
perceptions of realities, of indirectly expressing paradoxical human concerns, they have consumer relevance because these realities and concerns affect people's daily lives. Similarly, these perceptions of E10 helped to form stories that were repeated in the daily lives of motorists. These stories eventually became generalized and universal, as the grand myths that exist amongst consumers. Consequently, this shapes consumption behaviour, as is demonstrated by the Zimbabwean motorist community. We find that these stories can quietly die down especially when consumers are presented with no other choice.

\subsection{Characterisation of green fuel}

The study also reviewed blended fuel characterization and international standards, followed by a review of the success stories of the blend worldwide. These reviews were meant to deduce some lessons to improve the marketing of E10 fuel to potential consumers in Zimbabwe. In fact, the study of myths is in line with Levy (1981) who discusses the reasons why distinctions are made between tales and myths. He calls tales miniature myths and sees them all as susceptible to the same type of analysis (Levi, 1981). Drawing from the work of Levi (1981), we know that the fundamental character of a myth, points to its universal mode of thought and the way it transcends local culture. In fact Levi-Strauss says, "its substance does not lie in its style, its original music, or its syntax, but in the story which it tells" (Levi-Strauss, 1963: 210). As such, it is important to understand the E10 myths in Zimbabwe within the context of international standards, as this might help us to de-contextualise and re-contextualise the cultural meanings of E10 myths in Zimbabwe.

Ethanol intended for fuel use has to meet specific and regulated standards. In the USA, fuel ethanol must be anhydrous (less than 1 percent water). It must also be denatured (i.e. is made unfit for human consumption), usually prior to transport from the ethanol production facility, by adding 2 to 5 volume percent petroleum, typically pentanes plus or conventional motor gasoline. In many countries, ethanol fuel is principally used for blending in low concentrations with motor gasoline (petrol) as an oxygenate or octane enhancer. In high concentrations, it is used to fuel alternative-fuel vehicles specially designed for its use (World Ethanol Production, 2012). On the other hand, Green Fuel Limited's E10 is indeed anhydrous, meaning that moisture content is removed to achieve a $99,6 \%$ fuel grade ethanol that meets international standards (Green Fuel Limited, 2012). This provides an opportunity for Zimbabwe's E10 to be available for local consumption, and also for export, thus an assurance Zimbabwe's E10 is an internationally standardized product.

Consumers look to global brands to create an "imagined global identity," a transnational "global myth" of belonging anchored in consumer culture (Holt et al., 2004). Arnould and Thompson (2005) in support of Holt (2004) reflect that branded products are a preeminent source of mythic and symbolic resources for consumer identity projects. Thus, the fact that blended fuels are increasingly becoming preferable to consumers worldwide leaves Zimbabwe's ethanol marketers with a challenge to create an authentic identity for their product at a local level, rather than a global identity plagued with myths.

\subsection{Worldwide ethanol consumption and rankings}

By 2011, blends of E10 were used in more than twenty countries worldwide. This uptake of E10 was led by the United States, where almost all retail gasoline sold in 2010 was blended with $10 \%$ of ethanol. Blends from E20 to E25 have been used in Brazil since the late 1970s. E85 has been commonly used in the U.S. and Europe for flexible-fuel vehicles. Hydrous ethanol or E100 is used in Brazilian neat ethanol vehicles. Thus the U.S. and Brazil account for the majority of bio fuels operating capacity in the world, (GGE, 2012) together accounting for $87.1 \%$ of world production of 22.36 billion US gallons (84.6 billion litres) (Tomsk, 2006). Interestingly, Berg and Licht (2008) provide positive insights with regards to the consumption of ethanol worldwide. Within their work "Ethanol Fuel analysis and outlook", Berg and Licht (2008) postulate that the usage of ethanol fuel has grown over the years because of its environmental friendliness; reduction in overreliance on oil producing companies, and fuel imports; advancement of local technologies and knowledge base; and improved ethanol fuel technologies. The top 10 ethanol fuel producers are outlined in table 3. 
Table 3: Top 10 World Ethanol Fuel Producers

\begin{tabular}{ccc}
\hline Rank & Country & '000' Barrels per Day \\
\hline 1 & U.S.A. & 867.44 \\
2 & Brazil & 486.01 \\
3 & China & 37.00 \\
4 & Canada & 24.00 \\
5 & France & 18.00 \\
6 & Germany & 13.00 \\
7 & Thailand & 7.50 \\
8 & Australia & 6.50 \\
9 & Colombia & 4.80 \\
10 & Sweden & 3.50 \\
\hline
\end{tabular}

Source: Renewable Fuel Association, 2012

Zimbabwe occupies the position of 38 within the top 40 world rankings (World Ethanol Production Rankings, 2012) whilst in Africa it occupies the $4^{\text {th }}$ position out of the four African countries that are internationally recognised in terms of ethanol production. The top four ethanol producing countries in Africa are displayed in table 4.

Table 4: Ethanol Production rankings in Africa

\begin{tabular}{ccc}
\hline Rank & Country & '000 Barrels per Day \\
\hline 1 & Sudan & 0.50 \\
2 & Malawi & 0.20 \\
3 & Ethiopia & 0.10 \\
4 & Zimbabwe $^{*}$ & 0.02 \\
\hline
\end{tabular}

Source: Renewable Fuel Association, 2012

\subsubsection{Success factors for ethanol fuel adopters}

Strong incentives, coupled with other industry development initiatives, are giving rise to fledgling ethanol industries in countries such as Germany, China, Thailand, Spain, France, Sweden, Canada, India, Australia, and a couple of Central American countries (Renewable Fuels Association (RFA), 2012). Over and above this, the following have been some of the secrets in the success stories of the top-ranked ethanol producers and users:

$\checkmark$ Capital cost support

$\checkmark$ Direct Price Support

$\checkmark$ Income enhancing subsidies - for example income tax concessions

$\checkmark$ Guaranteed (captive) markets - for instance all government departments become captive market for E10

$\checkmark$ Price guarantees

$\checkmark$ Feedstock price support

Paradoxically, Zimbabwe has an abundance of resources to produce E10 fuel, and yet, consumers faced fuel shortages, as well as negative perceptions that were driven by consumer myths. Underlying the acceptance of these myths was the availability of alternative products.

\subsubsection{Green fuel usage transitions}

China and Japan are Zimbabwe's major sources of new and used car imports respectively. Ex-Japanese vehicles have flooded the Zimbabwean roads and market since dollarization of the economy, such that the generic pricing of cars has taken a downward trend. Apparently, China is ranked World's $3^{\text {rd }}$ in ethanol production (RFA, 2012), a clear indication that the self-contained country is advanced in ethanol advocacy.

Japan is successfully advocating for the use of Ethanol, and it has forged successful strategic alliances with Brazil, the world's leaders in ethanol, to supply the much needed product into the Japan's fuel pipelines. In July 2009, Japan's local media reported that the Niigata Prefecture (Japan) pioneered the sales of a mixture of gasoline and bioethanol 
made from rice for animal feed (RIA Novosti, 2013). During the same month, Japan Airlines found and proved that biofuel is more efficient than Petro-Fuel in a Test Flight, a move that has seen the airline joining a steadily expanding number of airlines trying to be seen as green and environmentally friendly through their fuel consumption strategies (McDermott, 2009).

\subsection{Mandatory blending of ethanol}

Due to the huge role played by ethanol in enhancing economic development of any country that handles the project(s) well, some top ranked ethanol-producing (and even non-ethanol-producing) countries have mandatory blending policies that support the many benefits of ethanol. Zimbabwe's neighbours, South Africa can be referred to as the latest case to introduce regulations regarding the mandatory blending of Bio-fuels with Petrol and Diesel, (Department of Energy, 2012).

In India, mandatory blending started in 2003, however it actually surfaced in the eyes of the public in 2004 (RFA, 2012). What is apparent from this experience is that if mandatory blending is to be introduced within Zimbabwe and mixed feelings (mostly political) are already prevalent (Zindoga, 2012) then some preliminary resistance is likely to occur, but acceptance may nevertheless eventually follow. In fact, mandatory blending has existed since 1976 within Brazil. And since 2007 the legal blend consists of approximately 25\% ethanol and 75\% gasoline (E25). Similarly, mandatory blending in Thailand was supported by tax reductions and investment subsidies. This has seen Thailand being ranked in the top ten producers of ethanol worldwide, pumping out about 75000 barrels per day (RFA, 2012). Similar to Thailand, Australia's mandatory blending was supported by tax exemptions and direct support. China on the other hand has mandatory blending in some regions that had some preliminary distribution and uptake challenges.

However, there are encouraging signs from Japan. Japan intends to fight global warming and surging oil prices by requiring that all vehicles on the road be able to run on an environment-friendly mix of ethanol and regular gasoline by 2030. The new policy was hailed by leading automakers; General Motors Corporation, Ford Motor Company and DaimlerChrysler AG's Chrysler Group, who have, to date, produced 5 million flexible fuel vehicles that can run on 85 percent ethanol. In line with this policy, all vehicles produced by Toyota Motor Corporation, the world's Number 2 automaker, already meet the 10-percent standard (Associated Press, 2006). Similarly, Kenya has an E10 mandate in place in Kisumu, the country's third largest city. Malawi has also has an E10 ethanol mandate in place, but is dependent on availability. Jamaica has an E10 ethanol mandate that took effect in 2011 (Biofuels Digest, 2011). These examples alone demonstrate the potential for success of E10 within Zimbabwe and the need for a positive consumer narrative and marketing strategy relating to E10 consumption within a Zimbabwean context.

\section{Conclusions and Managerial Implications}

As is evident from this study, world ethanol production will continue to grow at an increasing rate. The fact that Zimbabwe is included within the world rankings implies that the country has great consumption potential relating to E10. Results from the study demonstrate that there is a transparent marketing gap relating to the benefits of consuming E10 for the public within Zimbabwe. The benefits of consuming E10 needed to be communicated to the Zimbabwean public with the view to persuade them to consume the fuel and diminish consumer and man-made myths. However, these man made myths are encouraged by the availability of alternative product choices. For example, the E10 pricing was perceived as unjustified and too high for an indigenous innovation. This caused much resistance by the potential consumers, as motorists preferred the 'expensive' unblended petrol than E10, a local product, but "is only $3-5$ cents cheaper". Thus, it can be concluded that consumers and potential consumers perceive this difference as insignificant. And this is against the background of minds that are pre-occupied with mixed (negative) perceptions and myths relating to the performance of the product.

Our findings reveal that consumer mythology within the African context sells faster and potential consumers are more willing to believe mythology more than facts at times. Within the African cultural innuendoes, lies and fabricated half-truths sell faster than the truth. The truth is harder to believe, "it's too true to be true". Such has been the case in the initial phase of the ethanol fuel usage in Zimbabwe. For policy makers, these myths can be dispelled by limiting the availability of alternative products, and the myths will die a natural death.

From this study, we learn that consumer awareness of green fuels needs to be improved, particularly in developing economies. Further, consumers need to be made aware of the emotional factors relating to green consumption and ethical consumerism as this will encourage them to consume according to their morality (Wilk, 2002) as opposed to consumer mythology that emerges from social communities. This could be done in numerous ways such as through 
media advertising, trade fairs, newspapers, internet, workshops and other forums. Further, it would also be useful to engage the industry in forums and workshops. Potential consumers can also be offered opportunities to try the product, and be encouraged to make some comparative experiments, provide feedback. Managers can also make use of consumer testimonials, thereby making use of satisfied consumers to convince another potential consumer thus employing viral marketing and word of mouth marketing. Interestingly, it is word of mouth that has resulted in the consumer mythologies and it is therefore necessary to employ the same marketing methods to reverse consumers' negative perceptions of the product. Further, policy makers can limit the availability of fuels that are not environmentally friendly in order to encourage the consumption of green fuels.

\section{References}

Aggarwal, P., Cha T. and Wilemon D. (1998). "Barriers to the Adoption of Really-new Products and the Role of Surrogate Buyers", Journal of Consumer Marketing 15(4): 358-371.

Arnould, E. J. and Thompson C.J. (2005). "Consumer Culture Theory (CCT): Twenty Years of Research", Journal of Consumer Research, 31 (4): 868-882.

Associated Press. (2006). Japan to Require Cars to Run on Ethanol Gas. June, 29.

Atkin, D. (2004). The Culting of Brands: When Customers Become True Believers. New York: Portfolio.

Beck, U. (1992). Risk Society: Towards a New Modernity. Thousand Oaks, CA: Sage.

Benjamin, W. (1969). Illuminations. New York: Schocken Books.

Berg, C. and Licht F.O. (2008). World Ethanol Fuel: Analysis and Outlook. Ratzeburg, Germany.

Biofuels Digest (2011) Biofuels Mandates Around the World. [Online] Available: http://www.biofuelsdigest.com/bdigest/2011/07/21 /biofuels-mandates-around-the-world/ (10 November 2013).

Bristol, T. and Mangleburg T. F (2005). "Not Telling the Whole Story: Teen Deception in Purchasing", Journal of the Academy of Marketing Science, 33(1): 79-95.

Brown, S., McDonough, P. and Shultz C.J. II (2013). "Titanic: Consuming the Myths and Meanings of an Ambiguous Brand", Journal of Consumer Research, 40 (4):595-614.

Buttle, F. A. (1998). "Word of Mouth: Understanding and Managing Referral Marketing", Journal of Strategic Marketing, 6(3): 241-254.

Connolly, J. and Prothero, A. (2008). "Green Consumption: Life-politics, Risk and Contradictions", Journal of Consumer Culture 8 (1): 117-145.

Department of Energy, (2012). Regulations Regarding Blending of Biofuels with Petrol and Diesel. Pretoria, South Africa.

Douglas, M. (2001) 'Why Do People Want Goods?', in D. Miller (ed.) Consumption: Critical Concepts in the Social Sciences, pp. 262-71. London: Routledge.

Durgee, J.F. (1988). "Interpreting Consumer Mythology: a Literary Criticism Approach to Odyssey Informant Stories", NA - Advances in Consumer Research, in Houston M.J. Provo, UT : Association for Consumer Research: 531-536.

Gasparatos, A., Stromberg, P. and Takeuchi, K. (2013). Sustainability impacts of first-generation biofuels, Animal Frontiers, 3 (2), $12-26$.

Gentile, C. (2008). "Analysis: Brazil Pumps Ethanol to Japan", UPI Business News. December, 30.

Green Fuel Limited (2012). [Online] Available: http://www.greenfuel.co.zw/ (5 November 2012).

Holt D. B (2004). How Do Brands Become Icons: The Principles of Cultural Branding. Harvard: Harvard Business School Press.

Holt, D. B. and Thompson C.J. (2004). "Man-of-Action Heroes: The Pursuit of Heroic Masculinity in Everyday Consumption", Journal of Consumer Research, 31 (2), 425-440.

Holt, D. B., Quelch, J.A. and Taylor E.L (2004). "How Global Brands Compete", Harvard Business Review, 82 (9): 68-75.

Keller, E. (2007). "Unleashing the Power of Word of Mouth: Creating Brand Advocacy to Drive Growth", Journal of Advertising Research, 47(4):448-452.

Kotler, P. (1997). Marketing Management: Analysis, planning, implementation and control. 9th Edition. New Jersey: Prentice Hall.

Kozinets, R.V. (2001). "Utopian Enterprise: Articulating the Meaning of Star Trek's Culture of Consumption", Journal of Consumer Research, 28 (1): 67-89.

Kozinets, R. V. (2008). "Technology/ldeology: How Ideological Fields Influence Consumers' Technology Narratives", Journal of Consumer Research, 34 (6): 865-881.

Kristensen, D., Boye H., and Askegaard S. (2011). "Leaving the Milky Way! The Formation of Consumer Counter Mythology", Journal of Consumer Culture, 11 (2): 195-214.

Levy, S. (1981). "Interpreting Consumer Mythology: A Structural Approach to Consumer Behavior", Journal of Marketing, 45 (3):49-61.

Levi-Strauss, C. (1963). Structural Anthropology, Book I. New York: Basic Books.

Levi-Strauss, C (1969). The Raw and the Cooked: Introduction to a Science of Mythology, 1. New York: Harper and Row.

Libai B. A.., Lemon K. N. \& Hogan J. E (2004). "Quantifying the Ripple: Word-of-Mouth and Advertising Effectiveness", Journal of Advertising Research, 44, 271-280.

McDermott, M. (2009). Japan Airlines Find Biofuel More Efficient than Petrol-Fuel in Flight Test. January, 29.

Micheletti, M., Follesdal, A. and Stolle,D. (2004) Politics, Products, and Markets. London: Transaction Publishers.

Miller,D. (1998). A Theory of Shopping. London: Polity Press.

Renewable Fuels Association (2012). Annual Industry Outlook, Washington DC: RFA 
RIA Novosti (2013) Japan starts sales of biofuel made from rice. [Online] Available: http://en.ria.ru/world/20090718/155556467.html (20 December 2013).

Siddiqui, S., D. Turley, and F. Rifai. (2008). "Cries From The Goblin Market: Consumer Narratives in the Marketplace". In Advances in consumer research, vol. 35, eds. Angela Y. Lee and Dilip Soman, 810-811. Duluth, MN: Association for Consumer Research.

Smith, T. (1998). The Myth of Green Marketing: Tending Our Goats at the Edge of Apocalypse. Toronto: University of Toronto Press.

Strengers, Y. (2011). "Negotiating Everyday Life: The Role of Energy and Water Consumption Feedback", Journal of Consumer Culture 11 (3): 319-338.

Thompson, C. J. (2004). "Marketplace Mythology and Discourses of Power", Journal of Consumer Research, 31 (1):162-180.

Thompson, C.J. and Coskunner-Balli, G. (2007). "Enchanting Ethical Consumerism: The Case of Community Supported Agriculture", Journal of Consumer Culture 7 (3): 275-303.

Thompson, C.J., and Tian, K. (2008). "Reconstructing the South: How Commercial Myths Compete for Identity Value through the Ideological Shaping of Popular Memories and Countermemories", Journal of Consumer Research, 34 (5), 595-613.

Tulloch, J. and Lupton, D. (2002). "Consuming Risk, Consuming Science", Journal of Consumer Culture 2(3): 363-383.

Vincent, L (2002). Legendary brands: Unleashing the power of storytelling to create a winning market strategy. USA: Dearborn Trading Publishing.

Wallendorf, M. and Arnould, E.J. (1988). "We Gather Together: Consumption Rituals of Thanksgiving Day", Journal of Consumer Research 18 (1): 13-32.

Wilk, R. (2002). "Consuming Morality", Journal of Consumer Culture, 1 (2): 245-260.

Wood, S.L. and Lynch J.G. (2002). "Prior Knowledge and Complacency in New Product Learning", Journal of Consumer Research, 29 (3):416-426.

Zimbabwe Energy Regulatory Authority (2012). ZERA Statistics. Harare.

Zhao, X, and Belk, R.W. (2008). "Politicizing Consumer Culture: Advertising's Appropriation of Political Ideology in China's Social Transition", Journal of Consumer Research, 35 (2): 231-44.

Zindoga, T. (2012). Chisumbanje's Good Restart. The Herald, September 25. 